\title{
What do pollen-based quantitative reconstructions of plant cover tell us about past anthropogenic deforestation in Eastern China?
}

\author{
Furong Li ${ }^{1}$, X. Cao ${ }^{2}$, U. Herzschuh², X. Jia ${ }^{3}$, S. Sugita ${ }^{4}$, P.E. Tarasov ${ }^{5}$, M. Wagner 6 , Q. Xu , F. Chen ${ }^{8}$, A. Sun and \\ M.-J. Gaillard ${ }^{1}$
}

\section{Pollen proportions generally underestimate past open land cover in Eastern China. Pollen-based REVEALS reconstructions of plant cover in conjunction with archaeological and historical data provide more realistic descriptions of past anthropogenic deforestation than the scenarios commonly used by climate modelers.}

We present here examples of pollen-based REVEALS (Sugita 2007) reconstructions of past regional plant cover in Eastern China (Fig. 1) to demonstrate the potential of such reconstructions to (i) answer questions on past land-use and related land-cover change, and (ii) produce more realistic reconstructions of past anthropogenic land-cover change that can be used in the study of climate-landuse interactions in the past. For instance, the scenarios of past anthropogenic land-cover change commonly used by climate modelers (Klein Goldewijk et al. 2011) were shown to diverge significantly from other ALCC scenarios for several periods of the Holocene and regions of the globe, among other for Eastern China (Gaillard et al. 2010). China is one of the key regions of the globe where agricultural civilizations already flourished from ca. 7 ka BP and therefore plays an important role in land use-climate interactions over the Holocene. Pollen-based quantitative reconstructions of past land cover can be used to evaluate ALCCs (e.g. Kaplan et al. 2017). The REVEALS reconstructions presented here are part of a larger study within the PAGES' LandCover6k working group, covering temperate and northernmost subtropical China ( $\mathrm{L}$ 2016), and will be used to evaluate the existing ALCC scenarios in China.

Li (2016) uses the REVEALS model to estimate past regional plant cover from fossil pollen data with a standardized dataset of relative pollen productivity estimates (RPPs). Li (2016) groups several pollen records from

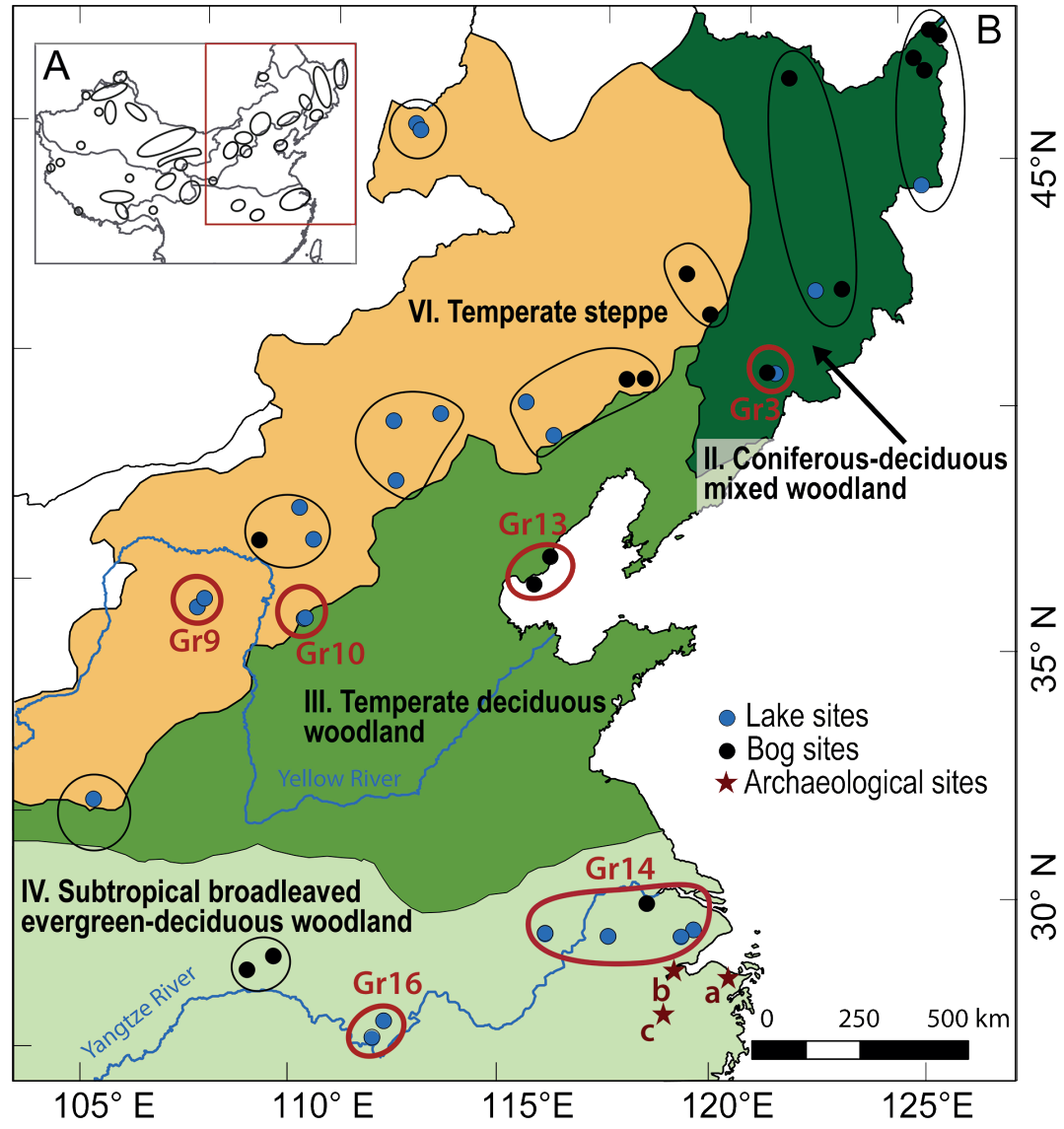

Figure 1: (A) Location of the study region. (B) Location of the site groups used for the pollen-based REVEALS reconstructions presented in this paper (dark red circles). Black circles indicate the additional site groups used in the full study by Li (2016). Dark red stars: location of the archaeological sites mentioned in the text: (a) Hemudu/ Tianluoshan; (b) Liangzhu; (c) Shangshan. the same region (e.g. site group 3, 9, etc. in Fig. 2) following the strategy adopted for Europe (Trondman et al. 2015) to increase the reliability of the REVEALS estimates. The time windows follow the standard scheme of the LandCover6k project, i.e. modern (age of the peat or lake-sediment sequence's top) to 0.1 ka BP, 0.1-0.35, 0.35-0.7 ka BP, and continuous 500-year intervals from 0.7 to $11.7 \mathrm{ka} \mathrm{BP}$. REVEALS estimates were calculated for the 31 taxa for which RPPs are available. Some plant taxa were then grouped into plant functional types (PFTs; Fig. 2), i.e. "temperate deciduous trees" (e.g. oak, ash, elm, linden) and "subtropical evergreen trees" (e.g. chinquapin, ring-cupped oak), and "other herbs and cultivated trees". PFT is a concept adopted by ecologists to represent broad groupings of plant species that share similar life forms and physiological mechanisms. In that sense, "other herbs and cultivated trees" is not exactly a PFT, but it rather groups all pollen types/plants that might have been part of human-modified vegetation due to agriculture. One of the dominant pollen types in this group is Artemisia (genus including up to 400 species in the world with diverse names such as mugwort, sagewort, wormwood, etc.). Chestnut and walnut are also included in "other herbs and cultivated trees" as species of both genera have long been cultivated in Eastern China, but walnut also grows in the temperate-deciduous woodland zone. The sedge family is included in the reconstruction, although plants from this family often grow locally at the study sites, which might be the case in site groups 9,13 and 14 .

Similar to Europe, herbaceous vegetation is strongly underrepresented in pollen percentages, and pine (Pinus) and birch (Betula) are overrepresented when compared with broad-leaved trees (Fig. 2). One taxon among herbs, Artemisia (see above), is strongly overrepresented by pollen. Therefore, in the cases where Artemisia is dominant in "other herbs and cultivated trees", the REVEALS estimated cover of total herbs or "open land" is lower than the pollen percentages, especially in site groups 3, 9 and 10 (Fig. 2).

\section{Do decreases in total tree cover reflect} anthropogenic land-use change? Open land is not necessarily due to human activities and changes in its cover do not need to be human-induced. There are ways 
II. Coniferous-deciduous mixed woodland Site group 3

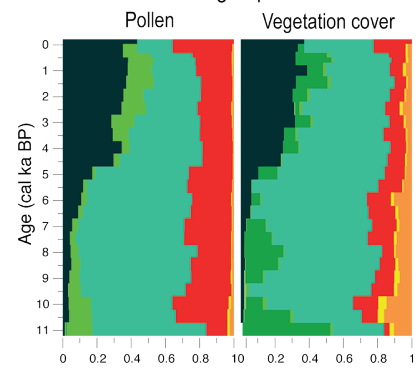

III. Temperate deciduous woodland Site group 13

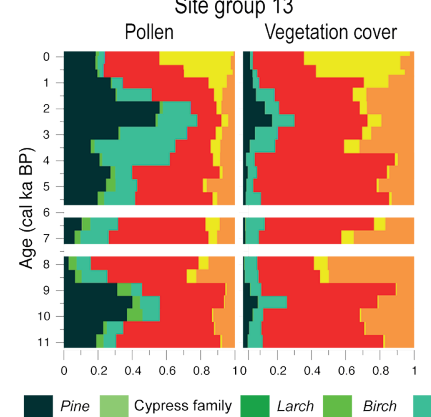

Total tree pollen/cover "woodland"
VI. Temperate steppe

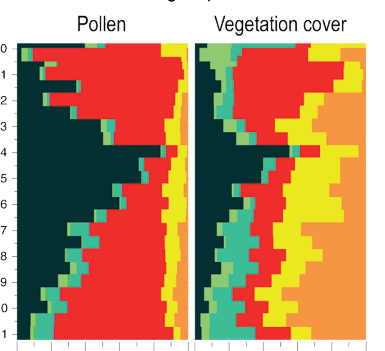

$\begin{array}{llllllll}0.6 & 0.8 & 10 & 0.2 & 0.4 & 0.6 & 0.8\end{array}$ IV. Subtropica Pollen
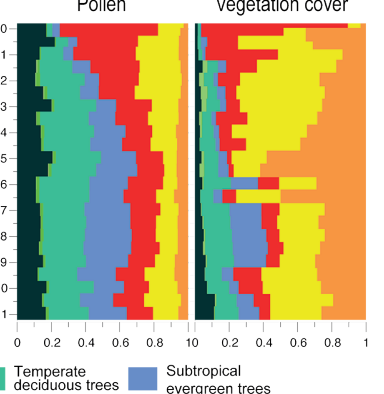

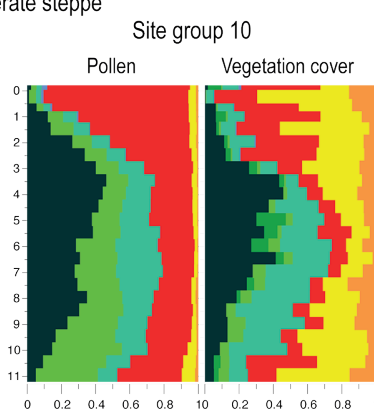

woodland Site group 16 Pollen Vegetation cover

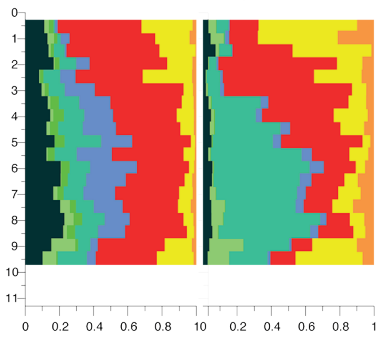

Other herbs and

Total herb pollen/cover "open land"

Figure 2: Comparison of pollen (left panel in each group of diagrams) with REVEALS estimates of plant cover, i.e. "vegetation cover" (right panel in each group of diagrams) in proportion for six site groups. "Temperate deciduous trees": ash, oak, linden, elm, rose family; "evergreen subtropical trees": chinquapin, ring-cupped oak, oleaster family, coffee family; "other herbs and cultivated trees": Artemisia (mugwort, sagewort, wormwood, etc.) hemp (Cannabis)/hop, buttercup family, aster/composite family, mustard family, pink family, amaranth/goosefoo families, morning glory family, legume family, mint family, lily family, knotweed/buckwheat family, chestnut tree and walnut tree.

to estimate the percentage of variation in pollen assemblages explained by, for example, climate versus human activities (Marquer et al. 2017), but these methods cannot extract the proportion of human-induced deforestation. Other lines of evidence such as archaeological and historical data syntheses are required to cross-check the interpretation of pollenbased land-cover change.

There is little change in wooded land cover over the Holocene in the southern part of the coniferous-deciduous mixed forest (II: site group 3). It suggests that human impact on the regional vegetation cover was weak except during the last 500 years, which the low number of archaeological evidence from this region also suggests. In the southern part of the temperate steppe zone (VI: site groups 9, 10), the total herb cover or "open land" (Fig. 2) increases at the expense of "woodland" from 6 ka (site group 10) and 4 ka BP (site group 9). Numerous archaeological sites in this region indicate widespread human activity during the Mid Holocene (Hosner et al. 2016), and foxtail millet and broomcorn millet remains suggest that domestication of crops started ca. 7.5 ka BP (Zhao 2014). The distinct increase in open land cover from ca. $6 \mathrm{ka}$ BP can therefore be assigned to large anthropogenic deforestation, with losses of ca. $40 \%$ (site group 9) to ca. $70 \%$ (site group 10) woodland cover between $6 \mathrm{ka} \mathrm{BP}$ and recent time (1500-1800 CE), and ca. 30\% (site group 10) to ca. $40 \%$ (site group 9) between 4 and $2.5 \mathrm{ka} \mathrm{BP}$. The distinct decrease in total tree cover or "woodland" from ca. 2 ka BP in the coastal area of the temperate-deciduous woodland zone (III: site group 13) probably relates to the first peak in population numbers at the beginning of the Han dynasty, 2.2-1.98 ka BP (Twitchett and Loewe 1995).

In the northern part of the subtropical broadleaved evergreen and deciduous woodland zone (IV: site groups 14,16), a clear increase in open land occurs from 6.5 and $7.5 \mathrm{ka} \mathrm{BP}$ in site groups 14 and 16 , respectively. The reconstruction from site group 14 ( 5 sites) is problematic for the time period 7-5.5 ka BP due to differences in timing of land-cover change between the sites or, more likely, problems of chronology for one or several sites. It is not possible, therefore, to date with certainty the age of the first loss in woodland cover (ca. 20-25\%) in the area from this reconstruction. The earliest date would be between ca. 7 and $6.5 \mathrm{ka} \mathrm{BP}$ and the younger date between ca. 6 and $5.5 \mathrm{ka} \mathrm{BP}$. A woodland-cover loss of ca. $15 \%$ occurred between ca. 1.5 and $1 \mathrm{ka} \mathrm{BP}$. The reconstruction from site group 16 shows a woodland-cover loss of ca. $35 \%$ between 6 and $4 \mathrm{ka} \mathrm{BP}$ and ca. $30 \%$ between 3.5 and $3 \mathrm{ka}$ BP. Pollen, charcoal and phytolith evidence at three archaeological sites in the lower Yangtze River region (Fig. 1) suggest that human influence started around $7 \mathrm{ka} B P$, substantial human impacts occurred at $4.7 \mathrm{ka} \mathrm{BP}$, and widespread human activities expanded around 2.8-2.2 ka BP (Atahan et al. 2008). Site group 14 is located close to the archaeological sites Shangshan (dated to ca. $10 \mathrm{ka}$ BP), Hemudu/Tianluoshan (7.5-6 ka BP), and Liangzhu (5.2-4.3 ka BP) (Fig. 1). Evidences from the Shangshan site suggest the use of rice by humans, but whether it is domesticated or wild rice is not clear. Evidences from the Hemudu and Tianluoshan sites indicate a transition process from domestication $\mathrm{ca}$ $7.5 \mathrm{ka} \mathrm{BP}$ to cultivation ca. $6 \mathrm{ka} \mathrm{BP}$, while the findings at the Liangzhu site suggest a rapid development of rice agriculture around ca. $5 \mathrm{ka}$ BP (Zhao 2010). The latter supports the pollen-based evidence of a significant early deforestation from ca. 6 ka BP (possibly earlier but not older than ca. $7 \mathrm{ka}$ BP) and a subsequent increase of woodland loss over the Midand Late-Holocene (from ca. 6-5.5 ka BP).

The examples above demonstrate the potential of pollen-based REVEALS reconstructions of past plant cover in conjunction with archaeological and historical data to quantify woodland loss due to deforestation over the Holocene. These reconstructions show good agreement with syntheses of archaeological studies indicating that humans transformed the landscapes of central-eastern temperate and northern China since ca. $7 \mathrm{ka} \mathrm{BP}$, with substantial increases of the number of archaeological sites recorded after ca. $7 \mathrm{ka}$ BP and between ca. 4.5 and $3 \mathrm{ka} \mathrm{BP} \mathrm{(e.g.} \mathrm{Wagner}$ et al. 2013; Wagner and Tarasov 2014). The REVEALS reconstructions also suggest that the HYDE 3.1 scenarios of Holocene anthropogenic land-cover change (Klein Goldewijk et al. 2011) commonly used in climate modeling strongly underestimate the degree of past anthropogenic deforestation in eastern temperate and northern subtropical China.

\section{AFFILIATIONS}

'Department of Biology and Environmental Science, Linnaeus University, Kalmar, Sweden

${ }^{2}$ Alfred Wegener Institute Helmholtz Center for Polar and Marine Research, Research Unit Potsdam, Germany ${ }^{3}$ School of Geographic and Oceanographic Sciences, Nanjing University, China

${ }^{4}$ Institute of Ecology, University of Tallinn, Estonia Institute of Geological Sciences, Free University of Berlin, Germany

${ }^{6}$ Eurasia Department, German Archaeological Institute, Berlin, Germany

Institute of Nihewan Archaeology, Hebei Normal

University, Shijiazhuang, China

${ }^{8}$ Institute of Tibet Plateau Research, Chinese Academy of Science, Beijing, China

'University of Chinese Academy of Sciences, Beijing, China

CONTACT

Furong Li: furong.li@Inu.se

\section{REFERENCES}

Atahan P et al. (2008) Quat Sci Rev 27: 556-570

Gaillard M-J et al. (2010) Clim Past 6: 483-499

Hosner D et al. (2016) Holocene 26: 1576-1593

Kaplan JO et al. (2017) Land 6: 91

Klein Goldewijk K et al. (2011) Glob Ecol Biogeogr 20: 73-86 Li F (2016) Linnaeus University Dissertations, Linnaeus University Press, 271/2016, 67 pp

Marquer L et al. (2017) Quat Sci Rev 171: 20-37

Sugita S (2007) Holocene 17: 229-241

Trondman A-K et al. (2015) Glob Change Bio 21: 676-697

Twitchett D, Loewe M (1995) The Cambridge history of China. Vol. 1: The $\mathrm{Ch}^{\prime}$ in and Han empires, 221BCAD220. Cambridge University Press, 1024 pp

Wagner M, Tarasov PE (2014) In: Renfrew C, Bahn P (Eds) The Cambridge World Prehistory, Vol. 2: East Asia and the Americas. Cambridge University Press, 742-764

Wagner M et al. (2013) Quat Int 290/291: 344-357

Zhao Z (2010) Archaeol Anthropol Sci 2: 99-105

Zhao Z (2014) Quat Sci 34: 73-84 